Classification

Physics Abstracts

07.05.Pj - 42.30.d - 81.70.Yp - 87.59.e - 91.90.+p - 95.75.Mn

\title{
Automatic Image Analysis Today
}

\author{
Jean-Louis Chermant $\left({ }^{1}\right)$ and Jean Serra $\left({ }^{2}\right)$ \\ $\left(^{1}\right)$ LERMAT, URA CNRS 1317, ISMRA, 6 bd Maréchal Juin, 14050 Caen Cedex, France \\ $\left({ }^{2}\right)$ CMM, École des Mines de Paris, 35 rue Saint Honoré, 77305 Fontainebleau Cedex, France
}

\begin{abstract}
Résumé. - Dans cet article nous rappelons le développement des techniques d'analyse d'images durant ce siècle et présentons brièvement les bases de l'analyse d'images et de la morphologie mathématique. On terminera par une vue des techniques utilisées à ce jour, avec une présentation de quelques applications venant de disciplines aussi variées que possible.
\end{abstract}

\begin{abstract}
In this paper, we recall the development of image analysis techniques during this last century and give briefly some basements of image analysis and mathematical morphology. The development of these techniques today and a presentation of some applications from different disciplines are also presented.
\end{abstract}

\section{Introduction}

William Thomson, English physicist and inventor, better known as Lord Kelvin (1869-1944), is often quoted as saying:

"When you can measure what you are speaking about and express it in numbers, you know something about it; but if you cannot express it in numbers, your knowledge is of a meager and unsatisfactory kind; it may be the beginning of knowledge, but you have scarcely, in your thoughts, advanced to the state of science, whatever the matter may be".

It is a forceful statement, which applies today to which we call quantitative image analysis, mathematical morphology, stereology and (partially) signal treatment and processing. These are classical tools for many disciplines, and are a set of methods based on mathematical concepts. From an image it enables, after various treatments, a quantitative description of the morphology (in the Greek sense, $\mu \mathrm{o} \rho \varphi \eta$ : shape (forme); $\lambda \mathrm{o} \gamma \mathrm{os}$ : speech (discours)) of objects and, consequently, information to be obtained on the effects of many types of parameters on these objects.

Due to its universality, image analysis is not a monolithic technique: the methods used depend mainly on the one hand on the nature of the images to be analyzed, and on the other hand on the goal pursued.

Image analysis can be divided in domains as a function of the goal envisaged:

- the first domain is concerned with the identification and the recognition of objects in order to make a classification or to take a decision: automatical sorting of mail [1], of bank checks, or 
of commercial orders by writing recognition; the sorting of objects in robotics, the speech or objects sorting on IR images belong also to this domain [2], although, the methods used are often based on syntactic nature,

- the second domain is concerned with the quantitative description of images, generally related to microscopic structures; it is thus commonly called quantitative microscopy or quantitative metallography by metallurgists; it is usually followed by a measurement.

\section{Historical Review}

The mathematical origin of image analysis dates back to that of geometrical probabilities, initially treated with the Pascal perspective of games of chance: Buffon in 1777 [3] solved the famous problem of the needdle falling onto a parquet floor made of parallel boards. This was followed by integral geometry [4-7], then the set theory leading to the development of the mathematical morphology, which has revolutionized automatic image analysis.

The first experimental method for image analysis was carried out by the mining engineer Delesse [8] who, in 1848, showed that there exists a rigorous proportionality between the surface area occupied on any cross section by a constituent of a homogeneous aggregate and the volume occupied by this constituent in the bulk rock:

$$
A_{\mathrm{A}}=V_{\mathrm{V}}
$$

A similar idea, but expressed in terms of absolute volume rather in proportions, appeared already in the work of the Italian mathematician Cavalieri, who showed, in 1635, that the volume of a particle observed in a three-dimensional space is equal to the sum of its section surfaces multiplied by the mean thickness of these sections (Cavalieri principle), [9]. More deeply, the great Arabian mathematician Ibn El Haytam (named also Alhazen (965-1039)) proved, in the 10th century, that the volume of the sphere was reached as the limit sum of the areas of its cross sections, as their thickness was tending towards zero [10]. When one knows that Ibn El Haytam was also a physician, and a physicist (he is considered as the founder of optics), his scientific profile actually makes him the "grandfather" of the stereologists.

Hence the first applications using manual methods go back more than one century, and the first stereological approaches to more than a millennium! However, automatic analysis appeared during the sixties, as a result of the progress in electronics. A further jump was made during the 1975-1980 years, with the introduction of numerical methods into computers. Whereas dedicated automatic apparata were largely used from 1980-1990 (Ibas, NS 1500, Omnicon, Pericolor, QTM, TAS, ...), after 1990 it became cheaper and sometimes more powerful to buy a specific software (Aphelion, Micromorph, Optimas, Visilog, Wit, ...), and to use in a microcomputor, with a frame graber card and a camera. Hardware solutions are nowdays limited to dedicated applications (e.g. tomography), and also to specific chips for image processing.

\section{Image Transformations}

Image analysis can be performed on any type of image: optical macrographs, confocal, infrared (IR), optical, positron emission tomography (PET), scanning electron, scanning force, tomograph, transmission electron, XR images; aerial photographs, ... No matter what image is to be analyzed, it has a support defined in a two-dimensional space, $\mathbb{R}^{2}$. After specific treatment and segmentation, the images can correspond either to an intersection of objects by a plane section (often called metallographic or biological section), or to the projection of objects contained in a thin slice. On such images one can identify, for example after metallographic etching or staining, 
the various materials present, phases or objects, which constitute a more or less connected set. To characterize them quantitatively, we have first to delineate the objects under study, and second to perform measurements on them. The present section is concerned by the first step, i.e. by the creation of electronic images.

The electronic sensors such as T.V. cameras and frame grabbers, or similar equipments, replace the continuous space by a regular grid, in which the 2-D images are expressed in terms of pixels (for picture elements), and the piles of 2-D images in voxels. All computorized treatments do work exclusively on this discrete information. As a general rule, images contain too much information, and one has to simplify them before performing measurements in order to make them significant. Here, the techniques may be regrouped into the two categories of filtering and of segmentation:

- filtering is a pre-treatment based essentially on linear [11], or morphological [12-15] operators, - segmentation aims to draw the contours of the objects of interest; the simplest way to do it is the threshold, but it is not the unique one; more sophisticated ones, such as the watershed, are often used.

None of these two steps is an obligation, and one can perfectly compute size distributions (for example) on non segmented grey tone images. For more details one can consult the books by Rosenfield and Kak [11], Serra [12] or Coster and Chermant [13].

\section{Image Measurements}

Suppose now that an object, say a set X, is ready to be measured. How to orient our choices among all possible types of measures? Three criteria, basically, have to be involved, namely invariances, stereology, and globality.

In practice, the objects to be measured are known up to a translation, up to some magnification and inside limited masks. Therefore, if we want to make ourselves free of these constraints, our measurements must be translation invariant, have a space dimension $\left(L, L_{2}, \ldots\right.$ or even zero), and be $\mathrm{C}$-additive (i.e. $\operatorname{mes}(\mathrm{X} \cup \mathrm{Y})+\operatorname{mes}(\mathrm{X} \cap \mathrm{Y})=\operatorname{mes} \mathrm{X}+\operatorname{mes} \mathrm{Y})$. Now, a classical theorem of integral geometry, due to Hadwiger [16], states that the unique measurements that fullfill the three above conditions and which are also rotation invariant and continuous for the convex sets, are the Minkowski functionals [17]. In two dimensions there are only three: area, perimeter, and number of grains minus number of holes, called Euler-Poincaré constant.

The second criterion of choice concerns how to interpret 2-D measurements in terms of 3-D space. Such investigations and answers have given rise to "stereology":

"Stereology is a three-dimensional interpretation of flat images, such as sections and projections, by criteria of geometric probability", [18].

Fortunately, all 3-D Minkowski functionals but one are obtained by averaging, under translation and rotation, the 2-D homolog ones. Hence 3-D volume, surface area, and mean width correspond respectively to area, perimeter and Euler-Poincaré constant. For this reason, they are called the basic stereological parameters.

Clearly, there are number of other features to be measured, such as size, dispersion, orientation, or shape for example. They are accessed either by other measurements (e.g. the Feret diameter), or more often by performing some morphological transformation before an area measurement. Then aspects such as size, clustering or anisotropy are brought into play by the morphological operator, and no longer by the measure itself. A typical example of this approach is given by the opening based granulometries [19].

The third criterion of choice deals with the fact that the working window $\mathrm{W}$ has the same scale as the object $\mathrm{X}$ itself, or its section, or has not. In the first case we can know the object (or its section) in full; in the second one we must introduce sampling procedures, hence probability concepts. A bridge from geometry to probability has been proposed by Matheron. He proved 
that when the centre of $\mathrm{W}$ is uniformly variable over the dilate of $\mathrm{X}$ by $\mathrm{W}$, then the intersection $\mathrm{X} \cap \mathrm{Y}$ becomes a stationary random set in a local sense, i.e. for all structuring elements smaller than W. This provides a meaning to notions such as volumic fraction, specific surface, porosity, etc... The basic stereological parameters extend to this case, as well as their relationships [20, 21].

We have presented this overview in the set case, for the sake of simplicity, but it is also valid for the grey tone images, considered as numerical functions [14].

\section{Recall on Mathematical Morphology}

The theory of Mathematical Morphology appeared in the late sixties via books [22, 23], paper [24] and patent [25], the former mainly in French. Matheron and Serra, the two originators of this method, developed a school of research which has produced, directly or indirectly, everything in the domain until 1985. Since this date, the theory has spread out rather widely, and independently describing the concept of opening and the Boolean model to study the relationships between the geometry of porous media and their permeability. The founders started in the line of Minkowski's work [17]. Indeed, the hit or miss transformation [12] generalizes Minkowski addition, and the opening [22] combines it with its dual form. They are in line with both integral geometry and geometrical probabilities, but with the difference that they wanted to transform a set into another, then into a third, ... rather than to associate measurements.

Three milestones marked the steps of the morphological construction: i) the book by Matheron [19] published in 1975 for the topological and probabilistic approach, which introduces new concepts as the granulometric axiom in image analysis, and invents the quasi-entirity of the set stochastic models used up to today; ii) the second, the book by Serra [12] which introduces explicitly the interaction approach between structuring element and properties which we want to measure; it is applied to non-increasing transformations based on hit or miss transformation; this set morphological approach is extended to numerical functions; iii) in the third book [14], Matheron and Serra extended the Euclidean-point level to lattices, which enable the theory of morphological filtering to be developed.

Mathematical morphology uses set type operations to transform an image [12,13]. In the translation invariant case, they are based on an element of known geometry, called structuring element. This tool is applied everywhere in the image and questions are asked about set relations which exist between this element and the set under study. The set of positive answers constitutes a new set with the morphological aspect looked for. The morphological information is contained entirely in the transformed image, the measurement constituting only a numerical quantification. The question related to the inclusion or intersection lead to the two main transformations: erosion and dilation, then to more complex transformations: opening (erosion followed by a dilation), closing (dilation followed by an erosion), and skeletonization (the set of points at an equal distance to the border of the object). Due to their set character, these transformations were first applied to threshold images, i.e. black and white images, then to images in grey tone levels. Finally a certain number of more complex transformations will enable by filtering or specific procedures (for example watershed [26] or other segmentation tools [27], or top-hat transformation [12]) the image to be simplified again and to be quantified, and to have a better segmentation, ...

Mathematical morphology can then be used to solve a certain number of problems - e.g. those related to interconnected phases, imbricated structures, grain boundaries un-detected by classical metallographic techniques, ... - for which stereology cannot give a satisfactory answer. We should not consider that mathematical morphology will replace classical stereology: if mathematical morphology enables transformation of images, the last step always remains a measurement of the same type as the measurement used in classical quantitative analysis methods. 


\section{Other Methods of Image Analysis}

Above we have reviewed the methods most often used, more specifically to quantify images using quantitative metallography. The methods used classically in pattern recognition or based on artificial intelligence concepts with or without an a priori knowledge can be concurrently utilized or in complement to mathematical morphology (see for example [28-30]). Among these last examples, one can cite neural networks, surely qualified to make a classification, the learning techniques, the a priori knowledge, or the use of vision experts. Fourier analysis can even be used to recognize the shape of objects or to characterize rough surfaces (see for example [31]).

Finally, the wish of some researchers to undertake spatial reconstruction and three-dimensional analysis from serial sections, projections or stereoscopic images, has led to the development of specific equipments, often sophisticated, to directly solve 3D problems: for example acoustic, confocal, laser or scanning force microscopy, or even nuclear magnetic resonance (NMR) or tomography (see for example [32-37]).

In addition to these automatic methods, biologists and more specifically pathologists, prefer to use manual tools, due to the complexity of their images, which are set on their images before any manual counting or via a digitizing table. The dissector, the fractionator and the nucleator tools are based most often on the Cavalieri principle [9], but there are many others such as the isector, the orientator, the selector, ... (see for example [38, 39]). Nevertheless, it is possible, in some cases of biological studies, to use the morphomator, i.e. any structuring element of mathematical morphology to solve these problems (see for example [40, 41]).

\section{Sampling}

The problem of sampling is probably, after that of the threshold, the most important and difficult step to perform correctly. Few investigations pay attention to this very important problem [42]. It is necessary for the frame of measurements to be statistical and that the number of measured objects to be large enough to avoid any bias. It is the use of the variogram which gives correct information on the surface of the objects to be measured with a given accuracy $[12,13]$.

Thereafter it remains only to determine the good strategy to select the fields of measurements.

\section{Development and Applications Today}

Today these techniques of image analysis are at an advanced stage and have been employed successfully to solve scientific and practical problems. Hence it cannot be ignored! For several years, the development of specific sensors and the means of transmission and storage permit the diffusion and manipulation of a larger and larger number of images. The present requirement is to develop efficient techniques to treat so much data in order to exploit them in large operational systems. This requires also some specific techniques such as data compression or fusion methods, the use of neural networks, of vision experts ....

These very powerful techniques enable not only quantitative characterization of objects, but also the establishment of relationships between the characteristics of the processes used and/or between properties, or to know accurately the structure of a biological organism as this is a prerequisite to understanding any biological function.

At present these methods are finding applications in the most varied disciplines. Moreover information provided by the images can appear similar, no matter the field of investigation [43]. 


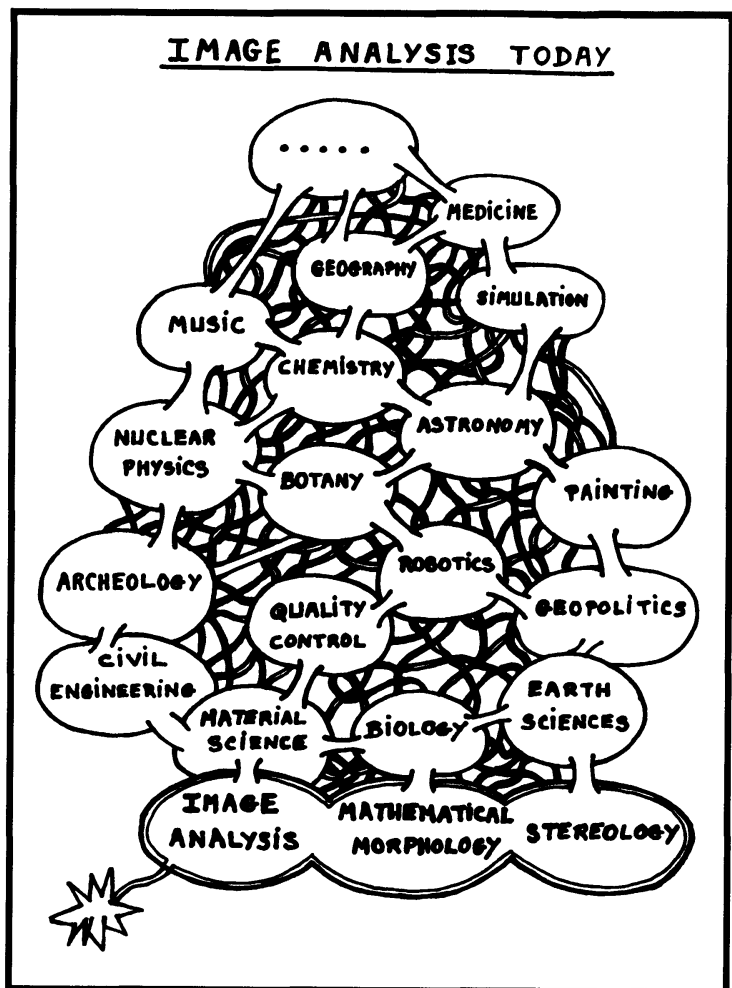

Fig. 1. - Some disciplines where image analysis, mathematical morphology and stereology are used (original cartoon from Dr Leszek Wojnar, Krakow, Poland).

Without claiming completeness, we list some examples from various disciplines (Fig. 1), as an illustration [43], thanks to many of my colleagues:

Archeology: reconstruction of very old irrigation networks from satellite images using top-hat transformation and specific filters [44],

Astronomy: discrimination of stars and galaxies from their brightness and the detected surface area [45],

Biology: size of cells, of neurons, or chromosome detection [46, 47],

Botany: development of leaves using or not using models [48], or selection and choice of wood for veneer in cabinetmaking from anisotropic investigation on sections [49],

Chemistry: acido-basic titrimetry from morphological transformations [50],

Demography: development of populations and inhabitant diffusion in urban periphery from variogram [51, 52],

Geography: degradation of the vegetal cover in a country from covariograms [53, 54], change in the corn or poppy fields from IR satellite images, or geodynamics investigations from satellite images [55],

Geology: phase organization and content, geological fall organization from the rose of directions [56], fracture quantification of rocks and seismography [57], or sedimentological investigation [58],

Materials: morphological investigation of steel [59], cast-iron [60], aluminium alloys, titanium 
alloys, superalloys [61], morphology-properties relationships (see for example [62-64]), or tridimensional separation of polyurethan balls by mathematical morphology [65],

Music: morphological transformation on music and creation of new opus, with Xenakis for example [66]: the intensity function of a sound as a function of time is equivalent to a function in grey tone levels as a function of the distance!,

Nuclear Physics: identification of particle tracks in irradiated detectors from histogram investigations [67],

Oceanography: detection of bottom mines and characterization of the seabed from sonar images [68],

Painting: scientific signature of painters from the brightness and saturation as a function of a distance parameter [69] or dating of a painting from the characteristics of extracted lines on $\mathrm{X}$ images [70],

Pathology: diagnosis of cancers [71], automatic screening of the cernix by mathematical morphology [72], clinical diagnosis,

Robotics: many applications are now in robotics, but they are closer to image processing, signal treatment and vision control; that is the case for quality control of wafers, of electronic cards, of packing of objects, or for target recognition, object tracking, for the analysis of motion (road or aircraft traffic control) [73],

Simulation: morphological simulation is more and more utilized, for example, in material science, to simulate oriented or spot structures from Boolean models [74-76], the sintering of ceramics from dead leaves model [77], or the evaporation in porous media by lattice gas models [78].

One should also mention the numerous military applications for object recognition, objects guidance, servocontrol, surveillance, tracking, ...

\section{Conclusion}

As we can see from the previous examples given and at the lecture of this "Microscopy, Microanalysis, Microstructures" issue (vol. 7 (1996) No5/6), automatic image analysis is a very powerful tool for many disciplines.

Moreover it becomes largely facilitated by the networks at the disposal of many laboratories: it is now possible to exchange and send not only softwares, but also images.

\section{Main References on Image Analysis, Mathematical Morphology and Stereology}

- Binet J.L., La cytologie quantitative (Presses Universitaires de France, 1977).

- Cau P., Microscopie quantitative: stéréologie, autoradiographie et immunocytochimie quantitative (Les Éditions INSERM, 1990).

- Chassery J.M. and Montanvert A., Géométrie discrète en analyse d'images (Hermès, 1991).

- Coquerez J.P. and Philipp S., Analyse d'image: filtrage et segmentation (Masson, 1995).

- * Coster M. and Chermant J.L., Précis d'analyse d'images (Les Éditions du CNRS, 1985); 2nd Edition (Les Presses du CNRS, 1989).

- De Hoff R.T. and Rhines F.N., Quantitative Microscopy (Mac Graw Hill, 1968); French translation by Montuelle J. (Masson, 1972).

- Elias H. and Hyde D.M., A Guide to Practical Stereology (Karger Pub. Comp., 1983).

- Exner H.E. and Hougardy H.P., Quantitative Image Analysis of Microstructure (DGM-Informationsgesellschaft Verlag, 1988).

\footnotetext{
* Books more dedicated to mathematical morphology
} 
- * Matheron G., Random Sets and Integral Geometry (J. Wiley, 1975).

- * Matheron G., Estimating and Choosing (Springer Verlag, 1989)

- Russ J.C., Practical Stereology (Plenum Press, 1986).

- Russ J.C., Computer-Assisted Microscopy: the Measurement and Image Analysis (Plenum Press, 1990).

- Saltykov S.A., Stereometric Metallography, in Russian, Metallurgia (1976).

- Saltykov S.A., Stereometrische Metallography, in German (VEB Deutscher Verlag für Grundstoffindustrie, Leipzig, 1974).

- Saxl I., Stereology of Objects with Internal Structure (Academia, Prague, 1989).

- Saxl I., Pelikan K., Rataj J. and Besterci M., Quantification and Modelling of Heterogeneous Systems (Cambridge International Science Pub., 1995).

- * Schmitt M. and Mattioli J., Morphologie mathématique (Masson, 1993).

- * Serra J., Image Analysis and Mathematical Morphology (Academic Press, 1982).

- * Serra J., Image Analysis and Mathematical Morphology, Vol 2: Theoretical Advance (Academic Press, 1988).

- Underwood E.E., Quantitative Stereology (Addison Wesley, 1970).

- Weibel E.R., Stereological Methods (Academic Press) Vol I \& II (1980).

\section{References}

[1] Belaid A. and Haton J.P., La Recherche 16 (1995) 1188.

[2] Horak R., Rev. Tech. Thomson-CSF 24 (1992) 971.

[3] Buffon G., Arithmétique morale, Chap. XXIII, Suppl. to the Histoire Naturelle, Paris (1777).

[4] Poincaré H., Calcul des probabilités, 2nd Edition (Carré, Paris, 1912).

[5] Kendall M.G. and Moran P.A.R., Geometrical Probability, London, C. Griffin, Ed. (1963).

[6] Santalo L.A., Introduction to Integral Geometry (Herman, Paris, 1953).

[7] Santalo L.A., Integral Geometry and Geometrical Probability, Encyclopedia of Mathematics and its Applications (Addison Wesley, Reading, Mass., USA, 1976).

[8] Delesse A., Ann. Mines 13 (1848) 379.

[9] Cavalieri B., Geometria degli indivisibili (1635).

[10] Ibn El Haytam, On the Measure of the Sphere (Qawl fi misahat al-Kura) ( 1000).

[11] Rosenfeld A. and Kak A.C., Digital Picture Processing (Academic Press, 1976).

[12] Serra J., Image Analysis and Mathematical Morphology (Academic Press, 1982).

[13] Coster M. and Chermant J.L., Précis d'Analyse d'Images (Les Presses du CNRS, 1985); 2nd Edition (Les Éditions du CNRS, 1989).

[14] Serra J., Image Analysis and Mathematical Morphology; Vol. 2: Theoretical Advances (Academic Press, 1988).

[15] Zebouj R., Du pré-traitement à l'analyse d'images, Thèse de Doctorat de l'Université de Saint-Étienne (1988).

[16] Hadwiger H., Vorlesungen über Inhalt, Oberfläche und Isoperimetrie (Springer Verlag, Berlin, 1957).

[17] Minkowski, Math. Ann. 57 (1903) 447.

[18] Elias H. and Hyde D.M., A Guide to Practical Stereology, Karger (1983) p. 16.

[19] Matheron G., Random Sets and Integral Geometry (Wiley, 1975).

[20] De Hoff R.T. and Rhines F.N., Quantitative Microscopy (Mac Graw Hill, 1968). 
[21] Underwood E.E., Quantitative Stereology (Addison Wesley, 1970).

[22] Matheron G., Eléments pour une thèorie des milieux poreux (Masson, 1967).

[23] Serra J., Introduction à la morphologie mathématique. Cahiers du Centre de Morphologie Mathématique, Vol 3 (École des Mines Pub., Paris, France, 1969).

[24] Haas A., Matheron G. and Serra J., Ann. Mines 11 (1967) 736; 12 (1967) 767.

[25] Patent of the texture analyzer (inventor Jean Serra), IRSID patent, French deposit n ${ }^{\circ} 499052$ on July 2, 1965, extended to Europe, Japan, USA.

[26] Meyer F. and Beucher S., J. Visual Communication and Image Representation 1 (1990) 21.

[27] Coquerez J.P. and Philipp S., Analyse d'image: filtrage et segmentation (Masson, 1995).

[28] Dougherty E.R. and Giardina C.R., Image Processing. Continuous to Discrete. Vol. 1: Geometric Transform and Statistical Methods (Prentice and Hall, 1987).

[29] Giardina C.R. and Dougherty E.R., Morphological Methods in Image and Signal Processing (Prentice and Hall, 1988).

[30] Pratt W.K., Digital Image Processing, 2nd Edition (Wiley Interscience Pub., 1991).

[31] Beddow J.K. and Meloy T., Testing and Characterization of Powder and Fine Particles (Heyden, London, 1980).

[32] Brakenhoff G.J., Blom P. and Barends P., J. Microsc. 117 (1979) 219.

[33] Kaufman L., Crooks L.E. and Margulis R., Nuclear Magnetic Resonance Imaging in Medicine, IgakuShoim, Ed. (New-York, Tokyo, 1981).

[34] Sorenson J.A. and Phelps M.E., Physics in Nuclear Medicine, Grune and Stratton Inc. (1987).

[35] 3DIPM, First International Conference on "3-D Image Processing in Microscopy”, Giessen, Germany, March 9-11, 1989. Eur: J. Cell Biol. 48 (1989) Suppl. 25.

[36] Micro 90, Transactions of the Royal Microscopical Society, New Series; Vol. 1: Micro 90. Proc. of the Royal Microscopical Society, Conference held in London (July 2-6, 1990). H.Y. Elden, Ed. (Adam Hilger Pub., 1990).

[37] Kordas G. and Kang Y.H., J. Amer: Ceram. Soc. 74 (1991) 709.

[38] Gundersen H.J.G., Bagger P., Bendtsen T.F., Evans S.M., Korbo L., Marcussen N., Møller A., Nielsen K., Nyengaard J.R., Pakkenberg B., Sørensen F.B., Vesterby A. and West M.J., APMIS 96 (1988) 857.

[39] Cruz Orive L.M. and Weibel E.R., Ann. J. Physiol. 258 (1990) L 148.

[40] Goyarts-Veldetre L., Van Driel-Kulker A.M.J., Ploem-Zaaijer J.J., Meyer F. and Ploem J.B., Microsc. Acta S6 (1983) 147.

[41] Meyer F. and Van Driel A., Quantitative Image Analysis in Cancer Cytology and Histology, J.Y. Mary and J.P. Rigaut, Eds. (Elsevier, 1986) p. 33.

[42] Matheron G., Estimating and Choosing (Springer Verlag, 1989).

[43] Chermant J.L., Acta Stereol. 11 (1992) 15.

[44] Merring C. and Debaine F., Proc. 9th Asian Conference on Remote Sensing (23-29 Nov. 1988), ACRS, Bangkok (1988) p B2.1.

[45] Slezak E., Bijaoui A. and Mars G., Astron. Astrophys. 201 (1988) 9.

[46] Dankaert T., Nguyen N.Q. and Hazout S., J. Microsc. Spectrosc. Electron. 12 (1987) 81.

[47] Royer J.P., Progr. Neurobiol. 37 (1991) 433.

[48] Kubinova L., Acta Stereol. 13 (1994) 115.

[49] Mariaux A., Peray O. and Serra J., Proc. 4th Int. Congress for Stereology, 4 ICS, Gaitherburg, USA, NBS, STP, 431 (1976) 257.

[50] Coster M. and Plancoulaine, 9th meeting of the French Section of the International Society for Stereology, ISS, Paris, France, (Feb. 6, 1986).

[51] Voiron-Canicio C., Thèse de l'Université de Nice (1991).

[52] Dauphine A. and Voiron-Canicio C., Variogrammes et structures spatiales, GIP Reclus, Collection Reclus modes d'emploi $\mathrm{n}^{\circ} \mathbf{1 2}$ (1988). 
[53] Merring C., Symp. for Remote Sensing, Proc. of the 22th ERIM, Abidjan, Côte d'Ivoire (20-26 Oct. 1988).

[54] Merring C. and Jacqueminet C., Acta Stereol. 6/III (1987) 951.

[55] Merring C., Huaman-Rodrigo D., Chorowicz J., Deffontaines B. and Guillande R., Technophysics 259 (1996) 153.

[56] Niorthe D., Quantification de paramètres structuraux de massifs rocheux en sites géotechniques par analyse automatique d'images, Thèse de Doctorat de l'École des Mines de Paris (1994).

[57] Keskes N. and Camy-Peyret J., Nature 350 (1991) 6.

[58] Verrechia E.P., Math. Geol. 28 (1996) 87.

[59] Petitgand H. and Osmont P., Rev. Mét. Sci. Génie Mat. 91 (1994) 243.

[60] Fargues J. and Stucky M., Rev. Mét. Sci. Génie Mat. 91 (1994) 267.

[61] Hazotte A. and Lacaze J., Rev. Mét. Sci. Génie Mat. 91 (1994) 277.

[62] Rhines F.N., Microstructurology (Dr Rieder-Verlag, GmbH, 1986).

[63] Tenckhoff E. and Vöhringer O., DGM Informationsgsellschaft Verlag (1990).

[64] Michelland-Abbé S., Coster M., Chermant J.L. and Mordike B.L., Script. Met. Mat. 25 (1991) 1309.

[65] Gratin C. and Meyer F., Acta Stereol. 11 (1992) 551.

[66] Benhamou M., Morphologie mathématique et musique. Report at Centre d'Etudes de Mathématique et Automatique Musicale (CERMAMU) (1983).

[67] Chermant J.L., Chermant L. and Tostain P., 15th meeting of the French Section of the International Society for Stereology, ISS, Paris, (Feb. 6, 1992).

[68] Faure E. and Le Gall J., Rev. Tech. Thomson CSF 24 (1992) 957.

[69] Gourdon A., Segmentation couleur de tableaux appliquée à l'étude du rapport des objets entre eux. Rapport de stage, École des Mines de Paris (1990).

[70] Duclairoir X., Rouquet R., Serra J. and De Couessin C., J. Microsc. Spectrosc. Elect. 12 (1987) 95.

[71] Baak J.P.A., Quantitative Pathology in Cancer Diagnosis and Pronosis (Springer Verlag, 1991)

[72] Meyer F. and Van Driel-Kulker A.M.J., J. Microsc. Spectrosc. Electron. 12 (1987) 23.

[73] Beucher S., Blosseville J.M. and Lenoir F., Spie, Intelligent Robots and Computer Vision: Sixth in a Series, Vol. 848 (1987) 648.

[74] Jeulin D., Modèles morphologiques de structures aléatoires et de changement d'échelle, Thèse de Doctorat ès Sciences Physiques, Caen (1991).

[75] Jeulin D., Sign. Proc. 16 (1989) 403.

[76] Quenec'h J.L., Jeulin D., Coster M. and Chermant J.L., in "Advances in Theory and Applications of Random Sets", Proc. Intl. Symp., 9-11 Oct. 1996, Fontainebleau, France, D. Jeulin, Ed. (World Scientific Pub. Comp., 1997) pp. 231-249.

[77] Jeulin D., Villalobos I.T. and Dubus A., Microsc. Microanal. Microstruct. 6 (1995) 371.

[78] Appert C., Melayah A., Pot V., Rothmare D.H. and Zaleski S., Proc. Computational Methods in Water Resources'92, 9-11 June 1992, Denver, Colorado, T.F. Russel, Ed. (Computational Mechanics Pub., Southampton U.K.). 